\title{
DYNAMIC DEUTERIUM ENRICHMENT IN COMETARY WATER VIA ELEY-RIDEAL REACTIONS
}

YunXi Yao and Konstantinos P. Giapis

Division of Chemistry and Chemical Engineering, California Institute of Technology, Pasadena, California 91125, USA; giapis@cheme.caltech.edu Received 2016 October 4; accepted 2016 December 8; published 2017 January 19

\begin{abstract}
The deuterium-to-hydrogen ratio $(\mathrm{D} / \mathrm{H})$ in water found in the coma of Jupiter family comet (JFC) 67P/ Churyumov-Gerasimenko was reported to be $(5.3 \pm 0.7) \times 10^{-4}$, the highest among comets and three times the value for other JFCs with an ocean-like ratio. This discrepancy suggests the diverse origins of JFCs and clouds the issue of the origin of Earth's oceanic water. Here we demonstrate that Eley-Rideal reactions between accelerated water ions and deuterated cometary surface analogs can lead to instantaneous deuterium enrichment in water scattered from the surface. The reaction proceeds with $\mathrm{H}_{2} \mathrm{O}^{+}$abstracting adsorbed $\mathrm{D}$ atoms, forming an excited $\mathrm{H}_{2} \mathrm{DO}^{*}$ state, which dissociates subsequently to produce energetic HDO. Hydronium ions are also produced readily by the abstraction of $\mathrm{H}$ atoms, consistent with $\mathrm{H}_{3} \mathrm{O}^{+}$detection and abundance in various comets. Experiments with water isotopologs and kinematic analysis on deuterated platinum surfaces confirmed the dynamic abstraction mechanism. The instantaneous fractionation process is independent of the surface temperature and may operate on the surface of cometary nuclei or dust grains, composed of deuterium-rich silicates and carbonaceous chondrites. The requisite energetic water ions have been detected in the coma of 67P in two populations. This dynamic fractionation process may temporarily increase the water $\mathrm{D} / \mathrm{H}$ ratio, especially as the comet gets closer to the Sun. The magnitude of the effect depends on the water ion energy-flux and the deuterium content of the exposed cometary surfaces.
\end{abstract}

Key words: astrochemistry - comets: general - methods: laboratory: molecular - molecular processes

\section{INTRODUCTION}

The origin of water on Earth is still a mystery (Robert 2001). The current consensus is that at least some terrestrial water originated elsewhere in the solar system and was delivered to Earth by asteroids or comets (Robert 2001; Alexander et al. 2012; Ceccarelli et al. 2014). The criterion for determining whether a family of extra-terrestrial objects may have contributed to terrestrial water is the deuterium-tohydrogen ratio $(\mathrm{D} / \mathrm{H})$ in water found on the object (Bockelée-Morvan et al. 2015; Mandt et al. 2015). A match with the standard mean oceanic water (SMOW) ratio of $1.56 \times 10^{-4}$ is considered a positive, which is true for some meteorites originating from the outer asteroid belt (Alexander et al. 2012). Measurements of the D/H ratio for several Oort cloud comets (OCCs) show a value about twice as high as the SMOW, precluding OCCs as the source of Earth's water (BockeléeMorvan et al. 2015). In contrast, remote spectroscopic measurements in comets 103P/Hartley_2 (Hartogh et al. 2011) and 45P/Honda-Mrkos-Pajdusakova (Lis et al. 2013) yielded a positive match, suggesting that Jupiter family comets (JFCs) may be the primary carriers of extraterrestrial water to the oceans. This notion was undermined recently by in situ measurements in the coma of another JFC, 67P/Churyumov-Gerasimenko (Altwegg et al. 2015), which yielded a water $\mathrm{D} / \mathrm{H}$ ratio more than three times the SMOW and even higher than that for OCCs, thus challenging new theories on the origin of comets and supporting earlier models of deuterium distribution in the early solar system (BockeléeMorvan et al. 2015; Mandt et al. 2015).

The $\mathrm{D} / \mathrm{H}$ ratio in cometary water is calculated from a comparison of calibrated intensities of spectroscopic or spectrometric peaks for isotopic variants of water-derived species, e.g., $\mathrm{H}_{2} \mathrm{DO}^{+} / \mathrm{H}_{3} \mathrm{O}^{+}$(Balsiger et al. 1995), $\mathrm{HDO} / \mathrm{H}_{2} \mathrm{O}$ (Hartogh et al. 2011; Lis et al. 2013; Altwegg et al. 2015), and $\mathrm{OD} / \mathrm{OH}$ (Hutsemékers et al. 2008). Though measured in the gaseous coma, the $\mathrm{D} / \mathrm{H}$ ratio is assumed to be identical to that of the ice. Any interference with the production or detection of these gaseous species will alter the ratio and must be carefully considered (Blake et al. 1999; Brown et al. 2012). Given the abundance of normal water in cometary comae, most of the concern regarding accurate measurement pertains to the deuterated species. We present here experimental evidence for a new surface-mediated isotopic fractionation mechanism, which may cause a temporary increase in deuterated water species in comae in the presence of energetic water ions. The mechanism is driven by Eley-Rideal (ER) reactions of water ions with deuterium-rich cometary crust materials. Such gassurface reactions occur when reactive projectiles collide directly with surfaces containing adsorbates, which the projectiles abstract without surface equilibration (Rettner \& Auerbach 1994; Weinberg 1996). This dynamic process transfers deuterium locked in cometary materials to normal water, thereby enriching the gas phase in deuterated water. It occurs at hyperthermal collision energies $(10-200 \mathrm{eV})$, but it is independent of surface temperature (Yao \& Giapis 2016), as appropriate for cometary conditions.

\section{ENERGETIC WATER IONS AND DEUTERIUM- ENRICHED COMETARY MATTER}

The dynamic deuterium enrichment mechanism requires collisions of energetic water ions with surfaces of materials enriched with deuterium. All of these conditions are met in cometary environments during periods of activity. Here we focus on comet $67 \mathrm{P}$.

Energetic $\mathrm{H}_{2} \mathrm{O}^{+}$ions have been discovered in the coma of comet $67 \mathrm{P}$ at heliocentric distances between 3.6 and 2.0 au, produced by the photoionization of cometary $\mathrm{H}_{2} \mathrm{O}$ (Nilsson et al. 2015a, 2015b). Two populations have been found: (i) The first is comprised of "accelerated" water ions, formed over an extended source region far from the nucleus and then picked up 
by the solar wind electric field and accelerated along the Suncomet direction to energies between 120 and $800 \mathrm{eV}$ (Nilsson et al. 2015b). These ions bombard the nucleus surface with fluxes up to the solar wind flux until a diamagnetic cavity forms (Goetz et al. 2016). (ii) The second is comprised of "cold" water ions, formed near the nucleus and affected by the outgassing velocity of the parent neutrals. These ions move away from the nucleus and can reach energies between 10 and $50 \mathrm{eV}$; they are more persistent and have a flux density about two orders of magnitude higher than that of "accelerated" water ions (Nilsson et al. 2015b). Both ion populations undergo charge exchange with background neutrals as they traverse the coma-which implies that fast neutral $\mathrm{H}_{2} \mathrm{O}$ molecules must also be present in both directions, increasing the flux of energetic $\mathrm{H}_{2} \mathrm{O}$ in the extended coma.

Water ions in the extended coma are accelerated toward the nucleus, where they collide with the outer nucleus crust of 67P (Nilsson et al. 2015a, 2015b). This crust is dehydrated (Filacchione et al. 2016) and includes typical cometary minerals, such as olivine and pyroxene silicates (Krüger et al. 2015; Hilchenbach et al. 2016), and carbonaceous refractory materials (chondrites; Capaccioni et al. 2015; Fray et al. 2016). Likewise, "cold" water ions moving away from the nucleus will collide with dust particles in the extended coma, which have a chemical composition similar to that of the nucleus crust (Kofman et al. 2015; Schulz et al. 2015).

The remaining requirement for dynamic $\mathrm{D}$ enrichment is that the dust grains and nucleus crust materials are deuterium-rich at levels much higher than the SMOW. The Philae Lander was equipped to answer this question for the 67P nucleus but did not complete its mission. Fortunately, the Cometary Secondary Ion Mass Analyser (COSIMA) aboard the Rosetta spacecraft was able to collect and analyze several dust particles in the vicinity of the nucleus (Fray et al. 2016). Although COSIMA did not have enough sensitivity to resolve deuterated species, the organic components of 67P particles were found by Fray et al. to be analogous to "the insoluble organic matter (IOM) samples extracted from carbonaceous chondrites, such as the Orgueil and Murchison meteorites" and similar to the "highmolecular-weight organic matter in IDPs and ultracarbonaceous Antarctic micrometeorites." Both of these comparisons are significant. The former meteorites are well known for surface spots containing IOM extremely enriched with deuterium with $\mathrm{D} / \mathrm{H}=15,000 \pm 5000 \times 10^{-6}$, i.e., $100 x$ SMOW for the Orgueil meteorite (Remusat et al. 2007; Gourier et al. 2008). Furthermore, the hydrogen/carbon ratio in the cometary IOM is higher than the ratios in these meteorites (Fray et al. 2016), consistent with a larger abundance of $\mathrm{C}-\mathrm{H}$ radicals, including those attached to aromatic rings (benzylic radicals), which are the most isotopically exchangeable bonds and the richest in deuterium (Gourier et al. 2008).

Dust particles of cometary origin have also been sampled from comet 81P/Wild_2 (Stardust mission; Brownlee et al. 2004; McKeegan et al. 2006), collected in Earth's stratosphere (chondritic porous interplanetary dust particles, CP-IDPs; Messenger 2000), and recovered from Antarctic snow (ultracarbonaceous Antarctic micrometeorites, UCAMMs; Duprat et al. 2010). Such materials were found to have $\mathrm{D} / \mathrm{H}$ ratios higher than the SMOW, ranging from moderate excess $(1-3 \times$ in Stardust samples) to extreme D enrichments $(10-30 \times$ in UCAMMs, even up to $50 \times$ in CPIDPs) (Messenger 2000; Brownlee et al. 2004; McKeegan et al. 2006; Duprat et al. 2010). Given other surface enrichment mechanisms for Solar objects, e.g., spallation reactions (Stephant \& Robert 2014), it appears plausible that the 67P crust and dust surfaces contain excess D, bonded directly to primitive organics (Remusat et al. 2006) or in hydroxyl groups in silicates (Mahaffy et al. 2015). These D reservoirs may be tapped by energetic $\mathrm{H}_{2} \mathrm{O}^{+}$ions to produce deuterated water species, thus enriching the coma.

\section{EXPERIMENTAL}

Laboratory experiments were carried out in an ultra-high vacuum (UHV) ion scattering system, described elsewhere (Gordon \& Giapis 2005). Isotopically pure beams of $\mathrm{H}_{2} \mathrm{O}^{+}$, $\mathrm{HDO}^{+}$, and $\mathrm{D}_{2} \mathrm{O}^{+}$, with tunable energy and fluxes between 2 and $5 \mu \mathrm{A}$, were directed to oxidized $\mathrm{Si}$, highly ordered pyrolytic graphite (HOPG), and polycrystalline Pt surfaces, held at room temperature. High-purity $\mathrm{H}_{2}$ or $\mathrm{D}_{2}$ gases were dosed to the Pt surface using a tube situated $\sim 2 \mathrm{~cm}$ from the surface. Molecular hydrogen and deuterium dissociated spontaneously on the Pt surface. Surface coverage in H or D atoms was adjusted (but not measured) by changing the background $\mathrm{H}_{2}$ or $\mathrm{D}_{2}$ pressure. Since deuterium did not dissociate spontaneously on the $\mathrm{SiO}_{x}$ and HOPG surfaces, $\mathrm{D}_{2} \mathrm{O}^{+}$bombardment was used prior to the abstraction experiments, as explained below.

The water ions employed in the scattering experiments impinged on the various surfaces at a $45^{\circ}$ angle of incidence, and the scattered products were detected at a $45^{\circ}$ angle of exit. All products were chemically identified with a high-resolution mass spectrometer (Extrel QPS), and their translational energies were measured using a calibrated $90^{\circ}$-sector energy analyzer. All signals reported were normalized to the beam current at each incidence energy $\left(E_{0}\right)$.

\section{DYNAMIC H/D ISOTOPIC EXCHANGE IN SURFACE COLLISIONS}

We first demonstrate the $\mathrm{H} / \mathrm{D}$ isotopic exchange reaction with normal water on a model polycrystalline $\mathrm{Pt}$ surface covered with D atoms [hereafter, $\mathrm{Pt}(\mathrm{D})$ ], which proceeds as follows:

$$
\mathrm{H}_{2} \mathrm{O}^{+}+\mathrm{D} \rightarrow \mathrm{H}_{2} \mathrm{DO}^{*} \rightarrow \mathrm{HDO}^{+}+\mathrm{H} .
$$

$\mathrm{HDO}^{+}$is produced in a single collision of $\mathrm{H}_{2} \mathrm{O}^{+}$projectiles with a surface $\mathrm{Pt}$ atom via the formation of an excited monodeuterated hydronium state $\left(\mathrm{H}_{2} \mathrm{DO}^{*}\right)$, which subsequently preferentially loses a hydrogen atom because of $\mathrm{O}-\mathrm{H}$ bond compression or excitation in the $\mathrm{H}_{2} \mathrm{O}^{+}$projectile during the hard collision. Hyperthermal surface ionization (Danon \& Amirav 1990) ensures the dynamic formation of detectable $\mathrm{H}_{2} \mathrm{DO}^{+}$and $\mathrm{HDO}^{+}$, though neutral $\mathrm{HDO}$ must also be present. Figure 1 shows the energy distributions of key scattered products from the $\mathrm{H}_{2} \mathrm{O}^{+}$and $\mathrm{D}_{2} \mathrm{O}^{+}$bombardment of $\mathrm{Pt}$ at an incidence energy of $41 \mathrm{eV}$. Predictably, scattering on clean $\mathrm{Pt}$ (no adsorbed D) yields no $\mathrm{H}_{2} \mathrm{DO}^{+}$(Figure 1(a)). However, a peak is detected at $19 \mathrm{amu} / \mathrm{e}$ without $\mathrm{D}_{2}$ dosing (Figure 1(b)), which can be either $\mathrm{H}_{3} \mathrm{O}^{+}$or $\mathrm{HDO}^{+}$, though it is impossible to resolve with our mass spectrometer. Long UHV chamber baking and sputter-cleaning of the Pt surface make it unlikely that residual $\mathrm{D}_{2}$ in the vacuum system could populate the $\mathrm{Pt}$ surface with $\mathrm{D}$ atoms, which are required to form $\mathrm{HDO}^{+}$. The 

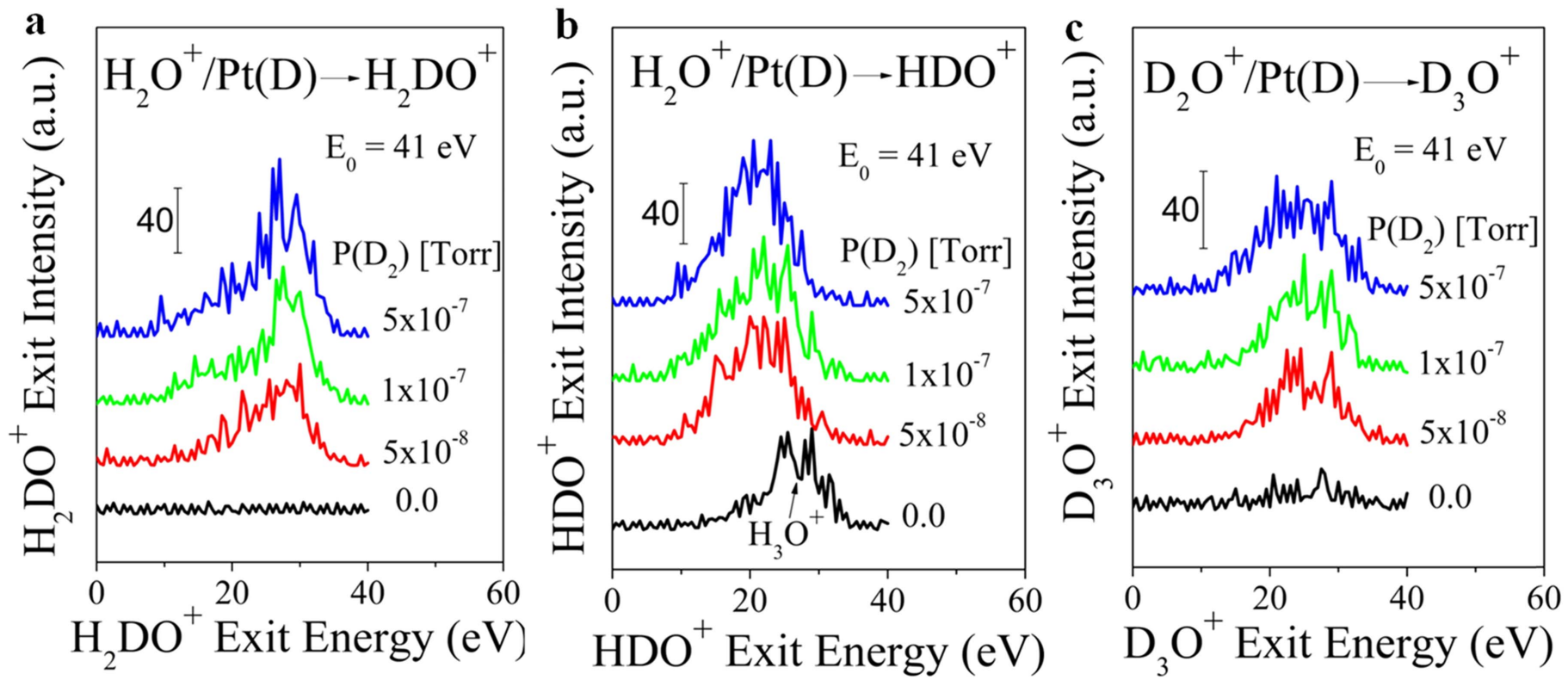

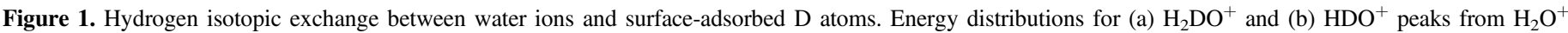

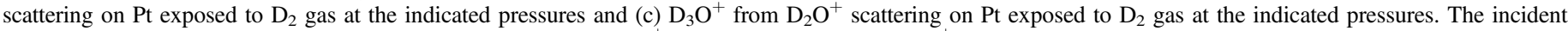
energy $E_{0}$ is $41 \mathrm{eV}$ for both projectiles. Note the formation of $\mathrm{H}_{3} \mathrm{O}^{+}$at $19 \mathrm{amu} / \mathrm{e}$ in (b) for $\mathrm{H}_{2} \mathrm{O}^{+} / \mathrm{Pt}_{\text {in }}$ the absence of adsorbed $\mathrm{D}$ at $P\left(\mathrm{D}_{2}\right)=0.0 \mathrm{Torr}$.

lack of detectable $\mathrm{H}_{2} \mathrm{DO}^{+}$at low incidence energies is consistent with this reasoning. In contrast, bombardment by the $\mathrm{H}_{2} \mathrm{O}^{+}$beam is expected to produce $\mathrm{H}$ atoms from the collision-induced dissociation of water ions, which can then be abstracted by other beam ions to form $\mathrm{H}_{3} \mathrm{O}^{+}$. Separate $\mathrm{H}_{2} \mathrm{O}^{+}$ beam experiments on $\mathrm{Pt}(\mathrm{H})$ produced strong $\mathrm{H}_{3} \mathrm{O}^{+}$signals (Figure 2(f)). The ultimate proof for hydronium ion formation versus $\mathrm{HDO}^{+}$lies in the different exit energies (vide infra).

Upon exposure of the Pt surface to $5 \times 10^{-8}$ Torr of $\mathrm{D}_{2}$ gas, which adsorbs dissociatively on Pt (Luntz et al. 1990), a 20 amu/e peak attributed to $\mathrm{H}_{2} \mathrm{DO}^{+}$is immediately observed, centered at $\sim 28 \mathrm{eV}$. The $\mathrm{H}_{2} \mathrm{DO}^{+}$peak intensity increases with the $\mathrm{D}_{2}$ pressure and saturates at $1 \times 10^{-7}$ Torr. The formation of $\mathrm{H}_{2} \mathrm{DO}^{+}$is dynamic: adsorbed $\mathrm{D}$ atoms are abstracted by the incident $\mathrm{H}_{2} \mathrm{O}^{+}$ions. Resonant neutralization precedes the hard collision of $\mathrm{H}_{2} \mathrm{O}$ with the substrate Pt atoms. At the distance of closest approach (apsis point), a transient state is formed, conjectured to be the elusive $\mathrm{H}_{2} \mathrm{DO}^{*}$ (Gellene \& Porter 1984), which on the rebound either loses an electron to form $\mathrm{H}_{2} \mathrm{DO}^{+}$ (Figure 1(a)) or undergoes dissociation to form $\mathrm{HDO}^{+}$ (Figure 1(b)). The scattered $\mathrm{HDO}^{+}$appears with an exit energy $\sim 5 \mathrm{eV}$ lower than the $19 \mathrm{amu} / \mathrm{e}$ peak observed without $\mathrm{D}_{2}$ dosing, which proves that the latter was $\mathrm{H}_{3} \mathrm{O}^{+}$(Figure 1(b)). The question arises then as to whether $\mathrm{H}_{3} \mathrm{O}^{+}$contributes to the $\mathrm{HDO}^{+}$peak under $\mathrm{D}_{2}$ exposure. We argue that any such contribution must be minor because when the $\mathrm{Pt}$ surface is saturated with $\mathrm{D}$ atoms, (i) the adsorption of $\mathrm{H}$ atoms from beam dissociation is suppressed, and (ii) the $\mathrm{H}_{3} \mathrm{O}^{+}$signal dies out at $E_{0}>61 \mathrm{eV}$ (Figure 2(f)), while $\mathrm{HDO}^{+}$persists to $E_{0}=111 \mathrm{eV}$ (Figure 2(b)). Additional measurements at $E_{0}=61 \mathrm{eV}$ (not shown) confirm that the $\mathrm{H}_{3} \mathrm{O}^{+}$signal is negligible versus $\mathrm{HDO}^{+}$.

Hydronium radical production via $\mathrm{ER}$ reaction is further confirmed by $\mathrm{D}_{2} \mathrm{O}^{+}$beam scattering on $\mathrm{Pt}$ (Figure 1(c)). A barely discernible $\mathrm{D}_{3} \mathrm{O}^{+}$peak is observed on clean $\mathrm{Pt}$ from the abstraction of surface $\mathrm{D}$ atoms, produced by the collisioninduced dissociation of $\mathrm{D}_{2} \mathrm{O}^{+}$. Upon $\mathrm{D}_{2}$ exposure, the $\mathrm{D}_{3} \mathrm{O}^{+}$ exit intensity jumps due to increased $\mathrm{D}$ atom coverage, but the signal saturates at $1 \times 10^{-7}$ Torr.

The reaction product kinematics, obtained by varying the $\mathrm{H}_{2} \mathrm{O}^{+}$incidence energy on $\mathrm{Pt}(\mathrm{D})$, corroborate the underlying ER reaction mechanism (Yao \& Giapis 2016). The scattered ions include $\mathrm{H}_{2} \mathrm{DO}^{+}, \mathrm{HDO}^{+}, \mathrm{H}_{2} \mathrm{O}^{+}$or $\mathrm{OD}^{+}$(18 amu/e), $\mathrm{OH}^{+}$, and $\mathrm{O}^{+}$(Figures 2(a)-(e)). All of these ions are shown below to have a common parent $\left(\mathrm{H}_{2} \mathrm{DO}^{*}\right)$. They are characterized by dynamic peaks, whose position varies with the $\mathrm{H}_{2} \mathrm{O}^{+}$incidence energy $\left(E_{0}\right)$. The $\mathrm{H}_{2} \mathrm{DO}^{+}$peak intensity decreases monotonically with $E_{0}$, and the peak dies out beyond $\sim 61 \mathrm{eV}$ (Figure 2(a)), suggesting an unstable reaction product. The $\mathrm{HDO}^{+}$peak (with minor contribution from $\mathrm{H}_{3} \mathrm{O}^{+}$) persists to higher energies $E_{0} \sim 111 \mathrm{eV}$. $\mathrm{HDO}^{+}$and $\mathrm{OD}^{+}$are clearly dissociation products of $\mathrm{H}_{2} \mathrm{DO}^{*}$ (Figure 2(c)). $\mathrm{H}_{2} \mathrm{O}^{+}, \mathrm{OH}^{+}$, and $\mathrm{O}^{+}$ion exits may originate from the late dissociation of either $\mathrm{H}_{2} \mathrm{DO}^{*}$ or unreacted beam ions (Figures 2(d), (e)). Energetic $\mathrm{H}^{+}$and $\mathrm{D}^{+}$are also detected, as well as negative ions $\mathrm{OD}^{-}$, $\mathrm{OH}^{-}$, and $\mathrm{O}^{-}$(not shown), formed by resonant electron attachment (Yao \& Giapis 2016).

The ER reaction proposed is schematically depicted in Figure 3(a), with five subsequent dissociation pathways for the excited $\mathrm{H}_{2} \mathrm{DO}^{*}$ intermediate. The ion exit energy data for $\mathrm{H}_{2} \mathrm{DO}^{+}, \mathrm{HDO}^{+}, \mathrm{H}_{2} \mathrm{O}^{+}$(or $\mathrm{OD}^{+}$), $\mathrm{OH}^{+}$, and $\mathrm{O}^{+}$, plotted in Figure 3(b), depend linearly on the incidence energy with slopes predictable a priori. The kinematic factor for $\mathrm{H}_{2} \mathrm{DO}^{+}$, calculated from binary collision theory to be 0.8233 , fits the energy data exceptionally well, a strong confirmation of its origin in an ER reaction (Yao \& Giapis 2016). The intercept of the linear fit, $-5.5 \mathrm{eV}$, represents inelastic energy loss and relates to the energy required to ionize $\mathrm{H}_{2} \mathrm{DO}^{*}$. If $\mathrm{HDO}^{+}$is produced from excited $\mathrm{H}_{2} \mathrm{DO}^{*}$, their respective kinematic factors should be linked: $K(\mathrm{HDO})=19 / 20 \times K\left(\mathrm{H}_{2} \mathrm{DO}\right)$. We thus obtain $K(\mathrm{HDO})=0.7821$, which captures the $\mathrm{HDO}^{+}$ energy data very well, validating the hypothesis. Similarly, the energy data for $\mathrm{H}_{2} \mathrm{O}^{+}$(or $\mathrm{OD}^{+}$), $\mathrm{OH}^{+}$, and $\mathrm{O}^{+}$can be linearly fitted with mass-weighted kinematic factors assuming they are fragments of the $\mathrm{H}_{2} \mathrm{DO}^{*}$ parent. It was noted above that $\mathrm{H}_{2} \mathrm{O}^{+}$, 

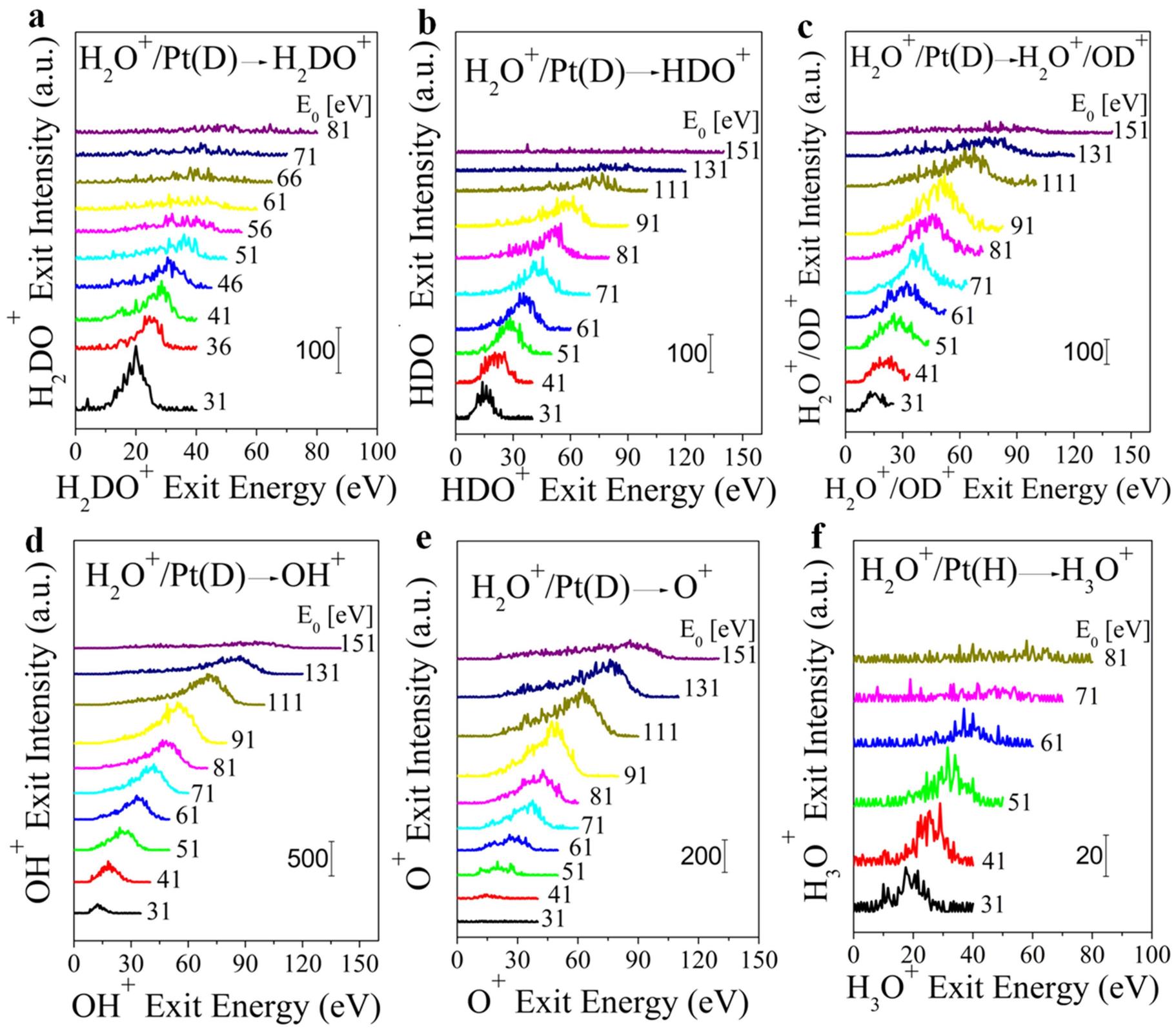

Figure 2. Energy distributions for scattered ions from energetic $\mathrm{H}_{2} \mathrm{O}^{+}$bombardment of $\mathrm{Pt}(\mathrm{D})$ and $\mathrm{Pt}(\mathrm{H})$. (a) $\mathrm{H}_{2} \mathrm{DO}^{+}$, (b) $\mathrm{HDO}^{+}$, (c) $\mathrm{H}_{2} \mathrm{O}^{+}$or $\mathrm{OD}^{+}$, (d) $\mathrm{OH}^{+}$, and (e) $\mathrm{O}^{+}$from $\mathrm{H}_{2} \mathrm{O}^{+}$scattering on Pt exposed to $1 \times 10^{-7}$ Torr $\mathrm{D}_{2}$ at room temperature. Results are shown as a function of the $\mathrm{H}_{2} \mathrm{O}^{+}$incidence energy $\left(E_{0}\right)$. (f) $\mathrm{H}_{3} \mathrm{O}^{+}$from $\mathrm{H}_{2} \mathrm{O}^{+}$scattering on $\mathrm{Pt}(\mathrm{H})$ at various $\mathrm{H}_{2} \mathrm{O}^{+}$incidence energies. Surface $\mathrm{H}$ atoms originate from the collision-induced dissociation of $\mathrm{H}_{2} \mathrm{O}^{+}$.

$\mathrm{OH}^{+}$, and $\mathrm{O}^{+}$can also be produced by $\mathrm{H}_{2} \mathrm{O}^{+}$scattering on clean Pt. In our experiment, however, the Pt surface is saturated with $\mathrm{D}$ atoms, and thus most of the $\mathrm{H}_{2} \mathrm{O}^{+}$projectiles are expected to interact with nearby $\mathrm{D}$ atoms, yielding the $\mathrm{H}_{2} \mathrm{DO}^{*}$ parent, which explains the remarkable linear fittings shown in Figure 3(b).

The proposed ER reaction mechanism is further tested in $\mathrm{D}_{2} \mathrm{O}^{+}$scattering experiments on $\mathrm{Pt}$, exposed to $1 \times 10^{-7}$ Torr $\mathrm{D}_{2}$ at room temperature. Here we detect $\mathrm{D}_{3} \mathrm{O}^{+}, \mathrm{D}_{2} \mathrm{O}^{+}, \mathrm{OD}^{+}$, $\mathrm{O}^{+}, \mathrm{OD}^{-}, \mathrm{O}^{-}, \mathrm{D}^{+}$, and $\mathrm{D}_{2}^{+}$(not shown). As before, the $\mathrm{D}_{3} \mathrm{O}^{+}$ ions are formed by ER reactions between $\mathrm{D}_{2} \mathrm{O}^{+}$and the adsorbed $\mathrm{D}$ atoms and are only stable at low incidence energies $(<60 \mathrm{eV})$. The exit energy of $\mathrm{D}_{2} \mathrm{O}^{+}$is lower than that of the corresponding $\mathrm{D}_{3} \mathrm{O}^{+}$, indicating that the former originates from the post-dissociation of the excited $\mathrm{D}_{3} \mathrm{O}^{*}$ intermediate instead of the directly scattered $\mathrm{D}_{2} \mathrm{O}^{+}$. Kinematic analysis shows that the $\mathrm{D}_{3} \mathrm{O}^{+}$ion exit energy data can be fitted well with a calculated kinematic factor of 0.8065 (Weinberg 1996). Again, the $\mathrm{D}_{2} \mathrm{O}^{+}, \mathrm{OD}^{+}$, and $\mathrm{O}^{+}$ion exit energies can be described very well assuming they are dissociation products of the excited $\mathrm{D}_{3} \mathrm{O}^{*}$ intermediate (Gellene \& Porter 1984).

The final demonstration of the isotope exchange reaction is done with cometary surface analogs: oxidized silicon $\left(\mathrm{SiO}_{x}\right)$ and graphitic carbon (HOPG) in lieu of silicate materials and carbonaceous chondrites. Since $\mathrm{D}_{2}$ does not dissociate spontaneously on these surfaces at room temperature, simple exposure to $\mathrm{D}_{2}$ no longer suffices. Bombardment of the $\mathrm{SiO}_{x}$ surface with energetic $\mathrm{D}_{2} \mathrm{O}^{+}$ions $(10 \mu \mathrm{A}, 30$ minutes, $E_{0} \sim 200 \mathrm{eV}$ ) readily introduces $\mathrm{D}$ atoms and, possibly, OD moieties to the $\mathrm{SiO}_{x}$ surface, denoted by $\mathrm{SiO}_{x}(\mathrm{D})$. When this surface doping process is stopped, a beam of normal $\mathrm{H}_{2} \mathrm{O}^{+}$ions scattering off $\mathrm{SiO}_{x}(\mathrm{D})$ immediately produces $\mathrm{H}_{2} \mathrm{DO}^{+}$ion exits (Figure 4(a)), though the signal weakens quickly as the surface $\mathrm{D}$ atoms are depleted. Since the probe beam now provides $\mathrm{H}$ 

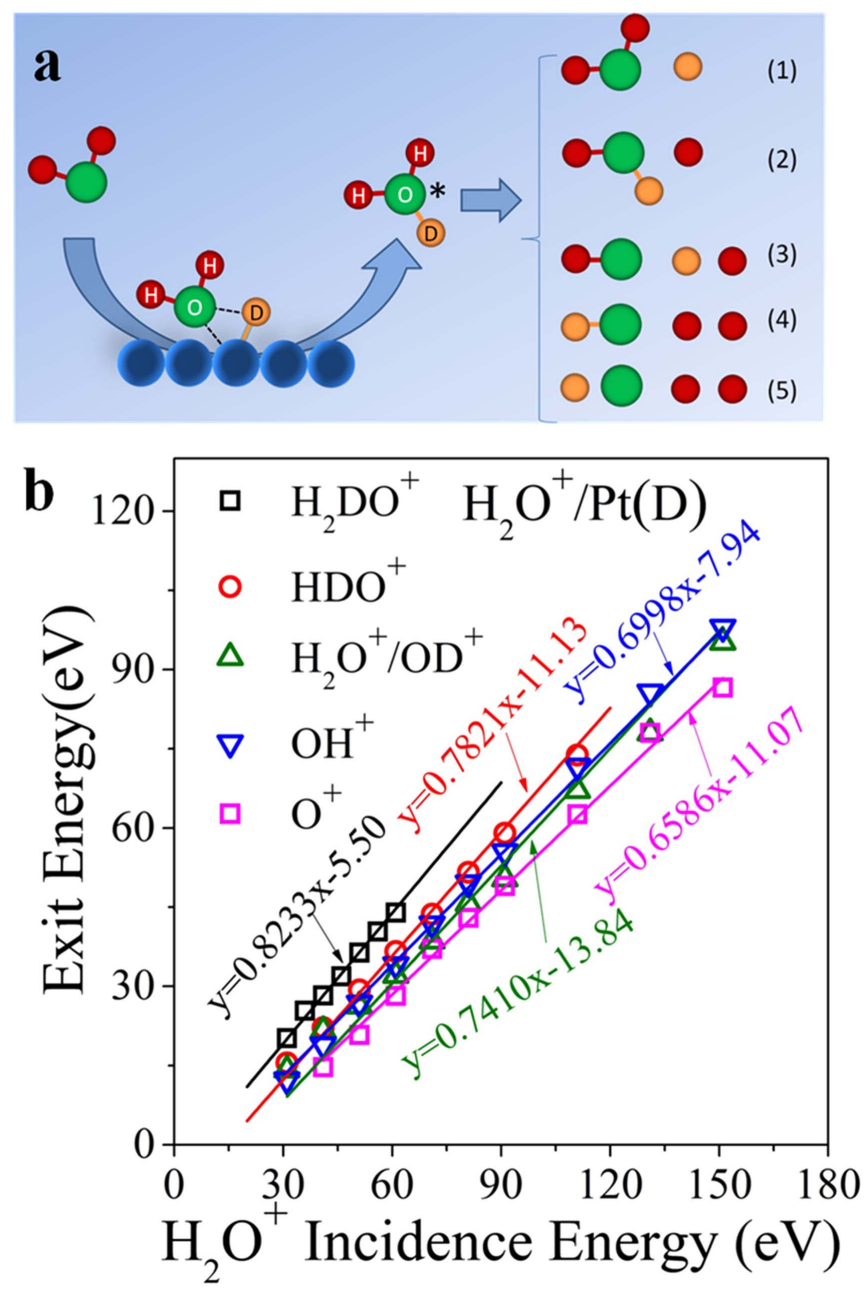

Figure 3. Reaction mechanism and kinematics of isotopic exchange between $\mathrm{H}_{2} \mathrm{O}^{+}$and surface-adsorbed $\mathrm{D}$ atoms. (a) Schematic depiction of the $\mathrm{H}_{2} \mathrm{O}^{+}$ion abstraction of adsorbed $\mathrm{D}$ to form an excited $\mathrm{H}_{2} \mathrm{DO}^{*}$ state with subsequent dissociation pathways. Channel (2) is preferred, as the $\mathrm{O}-\mathrm{H}$ bonds of the incident ion become excited and are more likely to break. (b) Ion exit energy data for $\mathrm{H}_{2} \mathrm{DO}^{+}, \mathrm{HDO}^{+}, \mathrm{H}_{2} \mathrm{O}\left(\right.$ or $\left.\mathrm{OD}^{+}\right), \mathrm{OH}^{+}$, and $\mathrm{O}^{+}$as a function of $\mathrm{H}_{2} \mathrm{O}^{+}$ incidence energy. The solid line for $\mathrm{H}_{2} \mathrm{DO}^{+}$represents a linear fitting with the slope calculated from modified binary collision theory (Yao \& Giapis 2016). The slopes for the linear fittings for $\mathrm{HDO}^{+}, \mathrm{H}_{2} \mathrm{O}$ or $\mathrm{OD}^{+}, \mathrm{OH}^{+}$, and $\mathrm{O}^{+}$are obtained by assuming they all originate from excited $\mathrm{H}_{2} \mathrm{DO}^{*}$ undergoing late fragmentation.

atoms to the $\mathrm{SiO}_{x}$ surface, unambiguous detection of the expected $\mathrm{HDO}^{+}$is precluded. However, this reaction process is confirmed by performing $\mathrm{D}_{2} \mathrm{O}^{+}$beam scattering on $\mathrm{SiO}_{x}(\mathrm{H})$ surfaces (Figure 4(b)). The $\mathrm{D}_{2} \mathrm{HO}^{+}$and $\mathrm{DHO}^{+}$signatures of the excited ER reaction intermediate $\mathrm{D}_{2} \mathrm{HO}^{*}$ are both detected (Gellene \& Porter 1984). We note that production of the hydronium state (and its isotopologs) is particularly enhanced at low incidence energies. The isotopic exchange reaction was also probed using a $\mathrm{HDO}^{+}$beam. Beam ions deposit both $\mathrm{H}$ and $\mathrm{D}$ atoms onto the $\mathrm{SiO}_{x}$ surface, which are abstracted randomly by other $\mathrm{HDO}^{+}$beam ions to form both $\mathrm{H}_{2} \mathrm{DO}^{*}$ and $\mathrm{D}_{2} \mathrm{HO}^{*}$ intermediates, as verified by their respective fragments (Figure 4(c)).

The isotopic exchange reaction was also demonstrated on HOPG. There are few $\mathrm{CH}_{x}$ groups present on the HOPG surface, whose $\mathrm{H}$ atoms may be abstracted. Indeed, bombardment of a pristine HOPG surface with $\mathrm{D}_{2} \mathrm{O}^{+}$ions gives rise to a $\mathrm{D}_{2} \mathrm{HO}^{+}$signal (Figure 5(a)), which decays quickly given the rapid depletion of the surface $\mathrm{H}$ atoms. During this experiment, energetic $\mathrm{D}_{2} \mathrm{O}^{+}$ions deposit $\mathrm{D}$ atoms onto the HOPG surface, producing ample $\mathrm{D}_{3} \mathrm{O}^{+}$signals and permitting the systematic study of ER reactions between $\mathrm{D}_{2} \mathrm{O}^{+}$ions and surface $\mathrm{D}$ atoms on HOPG (Figure 5(b)).

\section{DISCUSSION AND IMPLICATIONS}

Our experiments demonstrate that isotopic exchange between energetic water ions and deuterium atoms adsorbed onto or bonded to surfaces is a generic fractionation process occurring at incidence energies as low as $31 \mathrm{eV}$ and probably much lower. Thus, ER abstraction reactions could alter water $\mathrm{D} / \mathrm{H}$ ratio measurements in cometary comae, especially when energetic water ions interact with nucleus or dust grain surfaces enriched with deuterium. The new $\mathrm{D} / \mathrm{H}$ exchange mechanism proceeds through the formation of an excited mono-deuterated hydronium state, $\mathrm{H}_{2} \mathrm{DO}^{*}$ (possibly ionic), which subsequently dissociates to HDO or OD through preferential loss of collisionally excited $\mathrm{O}-\mathrm{H}$ bonds. Hydronium ions $\left(\mathrm{H}_{3} \mathrm{O}^{+}\right.$and $\mathrm{H}_{2} \mathrm{DO}^{+}$) have been detected in comae, e.g., 1P/Halley (Balsiger et al. 1986, 1995), and have several transitions that make them great candidates for remote spectroscopic evaluation of the water $\mathrm{D} / \mathrm{H}$ ratio. $\mathrm{H}_{3} \mathrm{O}^{+}$ions have also been detected in the $67 \mathrm{P}$ coma about $30 \mathrm{~km}$ from the nucleus between 3.09 and $2.8 \mathrm{au}$ (Fuselier et al. 2015). $\mathrm{H}_{3} \mathrm{O}^{+}$formation was attributed to gas-phase ion-molecule reactions: $\mathrm{H}_{2} \mathrm{O}^{+}+\mathrm{H}_{2} \mathrm{O} \rightarrow \mathrm{H}_{3} \mathrm{O}^{+}+\mathrm{OH}$. With a low outgassing rate $\left(\sim 10^{25}\right.$ molecules $\left./ \mathrm{s}\right)$, the mean free path for newly created $\mathrm{H}_{2} \mathrm{O}^{+}$ions near the comet was estimated to be $\sim 30 \mathrm{~km}$, suggesting that water ions "suffer at most one collision" before reaching the spacecraft. Given the low rate constant $\left(1.85 \times 10^{-9} \mathrm{~cm}^{3} \mathrm{~s}^{-1}\right)$ of the ion-molecule reaction (Fuselier et al. 2015), the observed $\mathrm{H}_{3} \mathrm{O}^{+}$abundance cannot be justified. In contrast, water ion collisions with dust grains have a much larger collision cross-section and are thus more likely to produce $\mathrm{H}_{3} \mathrm{O}^{+}$by abstracting adsorbed or bonded hydrogen in the grains. Such surface production mechanisms have not been considered in models of cometary comae. We note that water ion-surface collisions may also contribute to the observed sputtering of other surface species, such as refractory elements (Wurz et al. 2015).

The crux of the new isotopic fractionation process is the magnitude of the effect on the water $\mathrm{D} / \mathrm{H}$ ratio. Quantifying the enrichment can be done in the laboratory provided the water ion energy-flux and the deuterium enrichment in the 67P dust grains are known. Absent that, we can only provide a rough estimate. "Cold" water ions matter most, since their flux is typically 100 times the "accelerated" water ion flux and they possess kinetic energies between 10 and $50 \mathrm{eV}$, where the $\mathrm{D}$ atom abstraction reaction is favored. Nilsson et al. (2015b) provide flux estimates with the caveat that "the cold water ion flux can be severely underestimated due to the limited field of view at low energy." Fuselier et al. (2015) further state that "much less than 1 percent of the total ion flux" is detected. Thus, a measured "cold" water ion flux between $10^{10}$ and $10^{12} \mathrm{~m}^{-2} \mathrm{~s}^{-1}$ could actually be even higher than $10^{12}$ $10^{14} \mathrm{~m}^{-2} \mathrm{~s}^{-1}$, which corresponds to $\sim 5 \times 10^{19}-5 \times 10^{21}$ ions/s emitted from a sphere $4 \mathrm{~km}$ in diameter. The water production rate at the time of the $\mathrm{D} / \mathrm{H}$ measurement on $67 \mathrm{P}$ was $\sim 5 \times 10^{25}$ molecules/s (Fuselier et al. 2015). Thus, if all "cold" water ions were converted to HDO, this fractionation would add up to $100 \mathrm{ppm}$ of HDO to the water in the coma. A 

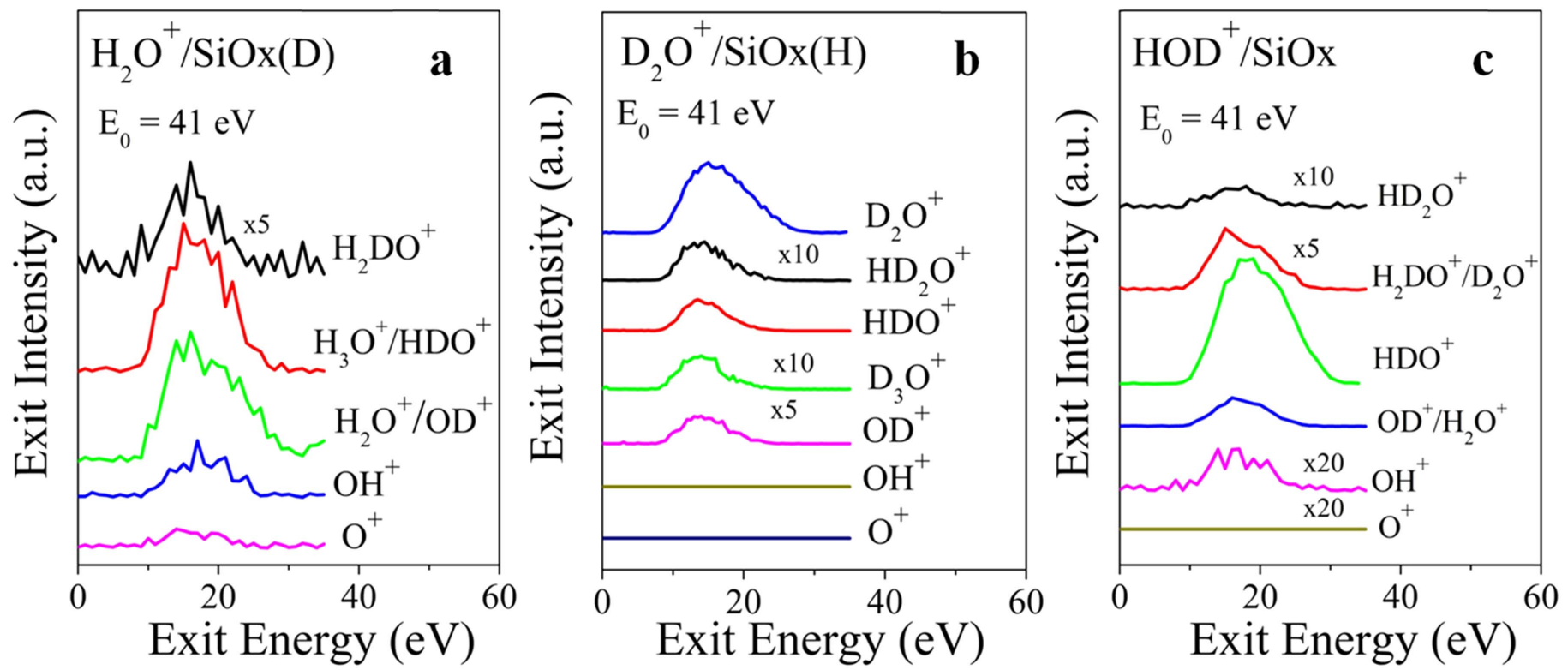

Figure 4. Isotopic exchange reaction on oxidized $\mathrm{Si}$ surfaces. Energy distributions for (a) $\mathrm{H}_{2} \mathrm{DO}^{+}, \mathrm{H}_{3} \mathrm{O}^{+}$or $\mathrm{HDO}^{+}, \mathrm{H}_{2} \mathrm{O}^{+}$or $\mathrm{OD}^{+}, \mathrm{OH}^{+}$, and $\mathrm{O}^{+}$from $\mathrm{H}_{2} \mathrm{O}^{+}$ bombardment of $\mathrm{SiO}_{x}$ doped with $\mathrm{D}$ atoms, which was produced by bombardment of the $\mathrm{SiO}_{x}$ surface with $\mathrm{D}_{2} \mathrm{O}^{+}$ions $\left(10 \mu \mathrm{A}, 30\right.$ minutes). (b) $\mathrm{D}_{2} \mathrm{O}^{+}, \mathrm{D}_{2} \mathrm{HO}^{+}$, $\mathrm{HDO}^{+}, \mathrm{D}_{3} \mathrm{O}^{+}, \mathrm{OD}^{+}, \mathrm{OH}^{+}$, and $\mathrm{O}^{+}$from $\mathrm{D}_{2} \mathrm{O}^{+}$bombardment of $\mathrm{SiO}_{x}$ doped with $\mathrm{H}$, which was produced by bombardment of the $\mathrm{SiO} x$ with $\mathrm{H}_{2} \mathrm{O}^{+}$ions $(10 \mu \mathrm{A}$, 30 minutes) and by the natural presence of $\mathrm{OH}$ groups on the $\mathrm{SiO}_{x}$ surface. (c) $\mathrm{HD}_{2} \mathrm{O}^{+}, \mathrm{H}_{2} \mathrm{DO}^{+}$or $\mathrm{D}_{2} \mathrm{O}^{+}, \mathrm{HDO}^{+}, \mathrm{OD}^{+}$or $\mathrm{H}_{2} \mathrm{O}^{+}, \mathrm{OH}^{+}$, and $\mathrm{O}^{+}$from $\mathrm{HDO}^{+}$ bombardment of $\mathrm{SiO}_{x}$. $\mathrm{HDO}^{+}$deposits both $\mathrm{H}$ and $\mathrm{D}$ atoms onto the $\mathrm{SiO}_{x}$ surface by collision-induced dissociation. The beam incidence energy for all water ions was set at $41 \mathrm{eV}$.
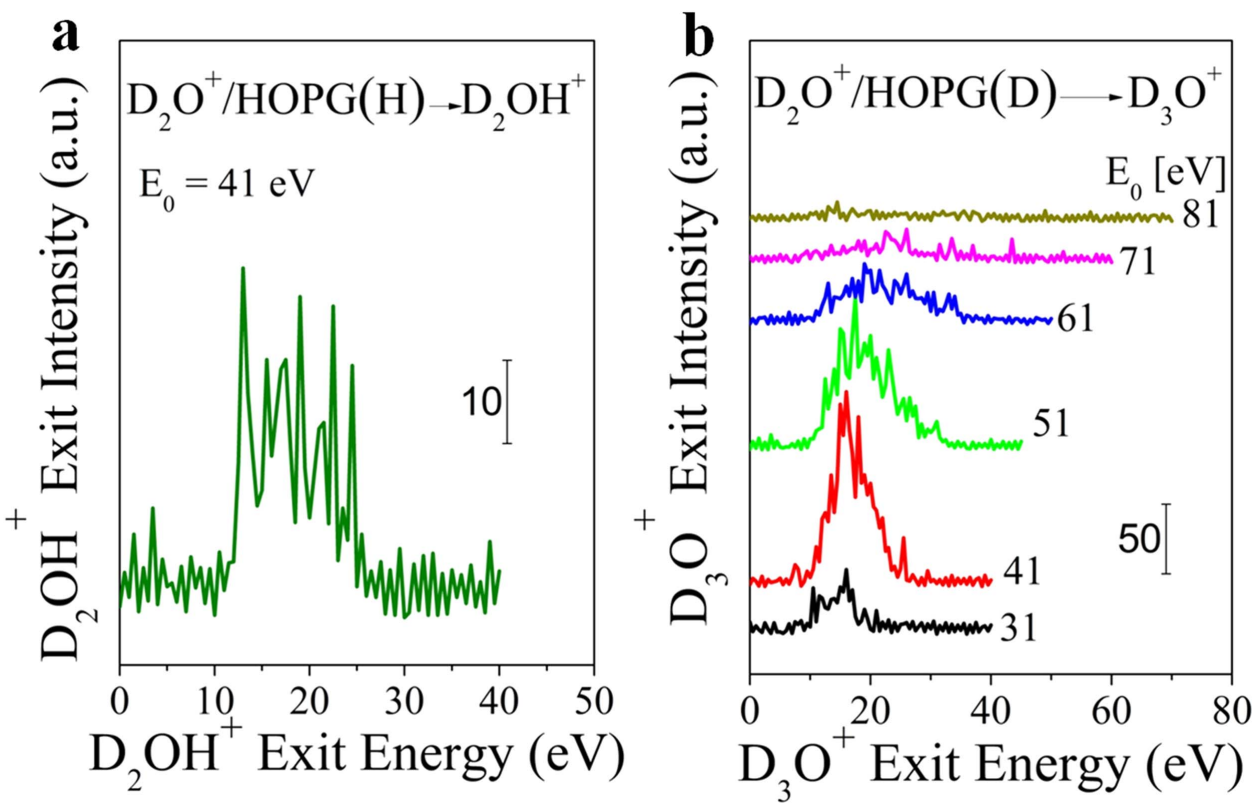

Figure 5. Isotopic exchange reaction on HOPG. (a) $\mathrm{D}_{2} \mathrm{OH}^{+}$signal from $\mathrm{D}_{2} \mathrm{O}^{+}$beam scattering on pristine $\mathrm{HOPG}$ surface at $E_{0}=41 \mathrm{eV}$. $\mathrm{H}$ atoms on the $\mathrm{HOPG}$ surface are sparse, probably naturally populated there, and get quickly depleted upon bombardment with $\mathrm{D}_{2} \mathrm{O}^{+}$ions. (b) $\mathrm{D}_{3} \mathrm{O}^{+}$ion exits from $\mathrm{D}_{2} \mathrm{O}^{+}$beam scattering on $\mathrm{HOPG}$ at various $\mathrm{D}_{2} \mathrm{O}^{+}$incidence energies. Surface $\mathrm{D}$ atoms are introduced from the collision-induced dissociation of $\mathrm{D}_{2} \mathrm{O}^{+}$ions.

yield of one is of course not realistic, even when extreme D enrichments in meteorites are assumed (vide supra). This estimate does not account for fast $\mathrm{H}_{2} \mathrm{O}$ neutrals from charge exchange collisions in the extended coma and from the scattering off of grains, possibly adding a considerable flux of energetic $\mathrm{H}_{2} \mathrm{O}$ molecules easily as high as that of the ions. Such energetic neutral $\mathrm{H}_{2} \mathrm{O}$ molecules are also capable of driving the same ER enrichment reactions and could relax the reaction yield requirement-but still supporting a $\mathrm{D} / \mathrm{H}$ change of $\leqslant 10 \%$.
Another possibility relates to HDO accumulation on the nucleus surface. As long as there are water molecules interacting with solar wind, energetic water ions will bombard the surface of the comet. At larger distances from the perihelion, the nucleus surface temperature is much lower, decreasing comet activity and producing less water vapor. Solar wind intensity is also lower, resulting in fewer "accelerated" water ions. However, these water ions will still collide with the nucleus surface, extract $\mathrm{D}$ atoms, and produce deuterated water. Given the rough cometary surface, many HDO molecules do 
scatter onto the surface, where they may freeze and thus accumulate. Integrating this effect over many years to and fro the aphelion, the nucleus crust may accumulate a layer of deuterated water, which is released on the next approach to the perihelion-still providing a dynamic enrichment effect.

Ultimately, the importance of the new isotopic fractionation mechanism depends on the magnitude of the water ion energyflux, particularly on whether the energetic water molecules in the jets can participate in enrichment reactions.

\section{PREDICTION}

Since the flux of both "cold" and "accelerated" water ions increases substantially as the comet moves closer to perihelion, the water $\mathrm{D} / \mathrm{H}$ ratio in the $67 \mathrm{P}$ coma should rise so long as no diamagnetic cavity forms (Goetz et al. 2016). Measuring the water $\mathrm{D} / \mathrm{H}$ ratio as a function of heliocentric distance was one of the stated goals of the Rosetta mission, but such data has yet to be reported.

This report was based on work funded by the NSF (Award No. 1202567).

\section{REFERENCES}

Alexander, C. M. O. D., Bowden, R., Fogel, M. L., et al. 2012, Sci, 337, 721 Altwegg, K., Balsiger, H., Bar-Nun, A., et al. 2015, Sci, 347, 1261952

Balsiger, H., Altwegg, K., Buhler, F., et al. 1986, Natur, 321, 330

Balsiger, H., Altwegg, K., \& Geiss, J. 1995, JGR, 100, 5827

Blake, A. G., Qi, C., Hogerheijde, M. R., Gurwell, M. A., \& Muhleman, D. O. 1999, Natur, 398, 213

Bockelée-Morvan, D., Calmonte, U., Charnley, S. B., et al. 2015, SSRv, 197, 47

Brown, R. H., Lauretta, D. S., Schmidt, B., \& Moores, J. 2012, P\&SS, 60, 166
Brownlee, D. E., Horz, F., Lewburn, R. L., et al. 2004, Sci, 304, 1764 Capaccioni, F., Coradini, A., Filacchione, G., et al. 2015, Sci, 347, 0628 Ceccarelli, C., Caselli, P., Bockelée-Morvan, D., et al. 2014, in Protostars and Planets VI, ed. H. Beuther et al. (Tuscon, AZ: Univ. Arizona Press), 859

Danon, A., \& Amirav, A. 1990, IJMSI, 96, 139

Duprat, J., Dobrică, E., Engrand, C., et al. 2010, Sci, 328, 742

Filacchione, G., De Sanctist, M. C., Capaccioni, F., et al. 2016, Natur, 529,368

Fray, N., Bardyn, A., Cottin, H., et al. 2016, Natur, 538, 72

Fuselier, S. A., Altwegg, K., Balsiger, H., et al. 2015, A\&A, 583, A2

Gellene, G. I., \& Porter, R. F. 1984, JChPh, 81, 5570

Goetz, C., Koenders, C., Richter, I., et al. 2016, A\&A, 588, A24

Gordon, M. J., \& Giapis, K. P. 2005, RScI, 76, 083302

Gourier, D., Robert, F., Delpoux, O., et al. 2008, GeCoA, 72, 1914

Hartogh, P., Lis, D. C., Bockelée-Morvan, D., et al. 2011, Natur, 478, 218

Hilchenbach, M., Kissel, J., Langevin, Y., et al. 2016, ApJL, 816, L32

Hutsemékers, D., Manfroid, J., Jehin, E., Zucconi, J.-M., \& Arpigny, C. 2008 , A\&A, 490, L31

Kofman, W., Herique, A., Barbin, Y., et al. 2015, Sci, 349, 0639

Krüger, H., Stephan, T., Engrand, C., et al. 2015, P\&SS, 117, 35

Lis, D. C., Biver, N., Bockelée-Morvan, D., et al. 2013, ApJL, 774, L3

Luntz, A. C., Brown, J. K., \& Williams, M. D. 1990, JChPh, 93, 5240

Mahaffy, P. R., Webster, C. R., Stern, J. C., et al. 2015, Sci, 347, 412

Mandt, K. E., Mousis, O., Marty, B., et al. 2015, SSRv, 197, 297

McKeegan, K. D., Aléon, J., Bradley, J., et al. 2006, Sci, 314, 1724

Messenger, S. 2000, Natur, 404, 968

Nilsson, H., Wieser, G. S., Behar, E., et al. 2015a, Sci, 347, 0571

Nilsson, H., Wieser, G. S., Behar, E., et al. 2015b, A\&A, 583, A20

Remusat, L., Palhol, F., Robert, F., Derenne, S., \& France-Lanord, C. 2006, E\&PSL, 243, 15

Remusat, L., Robert, F., \& Derenne, S. 2007, CRGeo, 339, 895

Rettner, C. T., \& Auerbach, D. J. 1994, Sci, 263, 365

Robert, F. 2001, Sci, 293, 1056

Schulz, R., Hilchenbach, M., Langevin, Y., et al. 2015, Natur, 518, 216

Stephant, A., \& Robert, F. 2014, PNAS, 111, 15007

Weinberg, W. H. 1996, AcChR, 29, 479

Wurz, P., Rubin, M., Altwegg, K., et al. 2015, A\&A, 583, A22

Yao, Y., \& Giapis, K. P. 2016, PhRvL, 116, 253202 